\title{
PENERAPAN VALUE ENGINEERING PADA PROYEK PEMBANGUNAN RSUD SANJIWANI GIANYAR DI MASA PANDEMI COVID-19
}

\author{
Aditya Permana Putra ${ }^{1}$, Anak Agung Gde Agung Yana ${ }^{2}$, I Nyoman Yudha Astana ${ }^{3}$ \\ ${ }^{1,2,3}$ Program Studi Magister Teknik Sipil Universitas Udayana \\ Email: aditcivilengineer@gmail.com
}

doi: https://doi.org/10.24843/SPEKTRAN.2021.v09.i01.p03

\begin{abstract}
ABSTRAK
Dalam pembangunan proyek konstruksi, biaya merupakan salah satu faktor penting yang menentukan keberlangsungan proyek. Pada studi kasus proyek pembangunan RSUD Sanjiwani Gianyar terdapat permasalahan bahwa terjadinya perubahan desain awal pada ruang isolasi terkait protokol COVID-19 yang menyebabkan kurangnya anggaran biaya rencana awal, sehingga perlu dilakukan penghematan biaya. Salah satu metode yang dapat digunakan untuk melakukan penghematan biaya yaitu metode Value Engineering (VE). VE adalah suatu metode pendekatan yang kreatif dan terencana dengan tujuan untuk mengefisienkan biaya-biaya yang tidak diperlukan. Tujuan dari penelitian ini adalah untuk menganalisis item-item pekerjaan yang berpotensi dihemat, menganalisis alternatif terbaik pengganti desain awal, dan menghitung besar penghematan biaya setelah dilakukan penerapan VE tersebut. Pada penelitian ini digunakan metode penelitian deskriptif kuantitatif. Analisis VE dilakukan dalam enam tahapan yaitu: tahap informasi, tahap analisis fungsi, tahap kreatif, tahap evaluasi, tahap pengembangan, dan tahap presentasi. Hasil analisis VE menunjukkan bahwa penghematan dapat dilakukan pada pekerjaan struktur beton dengan mengganti balok dan pelat konvensional menjadi balok precast dan pelat metal deck yang menghasilkan penghematan sebesar Rp1.046.477.531,18 atau 4,47\%, pada pekerjaan penutup lantai digunakan alternatif lantai keramik sebagai pengganti lantai granite tile didapat penghematan sebesar Rp1.058.532.387,51 atau 34,64\%, dan pada pekerjaan kusen, pintu, jendela digunakan alternatif daun pintu aluminium sebagai pengganti daun pintu plywood lapis HPL yang menghasilkan penghematan sebesar Rp117.598.489,53 atau 4,41\%. Total penghematan biaya setelah dilakukan analisis VE adalah sebesar Rp2.043.035.163,40 atau 1,50\% dari anggaran biaya awal.
\end{abstract}

Kata kunci: value engineering, penghematan, analisis fungsi, metode AHP, life cycle cost

\section{IMPLEMENTATION OF VALUE ENGINEERING ON SANJIWANI GIANYAR REGIONAL HOSPITAL PROJECT IN THE PANDEMIC OF COVID-19}

\begin{abstract}
In the construction project, cost is an important factor that determines the sustainability of a project. In the case study of the Sanjiwani Gianyar Regional Hospital construction project, there was a problem that the initial design of the isolation room changed related to the COVID-19 protocol caused a lack of budget plan, so it was necessary to save costs. One of the methods that can be used is Value Engineering (VE). VE is a creative and planned approach with the aim of streamlining unnecessary costs. The purpose of this research is to analyze work items that are potentially saved, to analyze the best alternative to replace the initial design, and to calculate the cost savings after implementation of the VE method. This research uses descriptive quantitative methods. VE method is carried out in six-phase, namely: the information phase, the function analysis phase, the creative phase, the evaluation phase, the development phase, and the presentation phase. The results of the VE analysis show that savings can be made on concrete structure work by replacing conventional beam and slab to precast beam and metal deck slab which results in savings of IDR 1,046,477,531.18 or 4.47\%. In floor finishing work, ceramic floors were used as an alternative to granite tile floors which result in savings of IDR 1,058,532,387.51 or $34.64 \%$. Then in frames, doors and windows work, an alternative to aluminum doors is used as a substitute for HPL-coated plywood doors which results in savingsof IDR $117,598,489.53$ or $4.41 \%$. The total cost savings by using VE analysis was IDR 2,043,035,163.40 atau 1.50\% of the budget plan.
\end{abstract}

Keywords: value engineering, cost savings, function analysis, AHP method, life cycle cost 


\section{PENDAHULUAN}

Biaya adalah salah satu faktor penting yang menentukan keberlangsungan dari suatu proyek, sehingga diperlukan suatu pengendalian agar biaya yang dikeluarkan menjadi efisien dan tepat sasaran (Bari et al., 2012). Pada umumnya pembangunan gedung akan melalui tahapan-tahapan yang kompleks dalam siklus hidup proyek. Tahap perencanaan akan sangat berpengaruh terhadap tahap pelaksanaan konstruksi (Serrador, 2012). Oleh karena itu, perlu adanya peninjauan kembali metode proyek yang digunakan dengan mengkaji ulang desain proyek terhadap pelaksanaan proyek sehingga memungkinkan untuk dapat dilakukan penghematan biaya (Diputera et al., 2018). Dalam manajemen rekayasa konstruksi terdapat suatu displin ilmu yang bertujuan untuk menghemat biaya yang bernama Value Engineering (VE). Menurut Dell'Isola (1982), VE adalah metode pendekatan yang kreatif dan terencana dengan tujuan untuk mengefisienkan biaya-biaya yang tidak diperlukan. VE dilakukan agar dapat menghemat biaya serta mengoptimalkan mutu dan fungsi yang mengacu pada suatu bangunan gedung (Jaya et al., 2019). Penerapan VE dalam bidang konstruksi menghasilkan penghematan yang besar dari segi waktu dan biaya (Klinger et al., 2006).

Pada penelitian ini penerapan VE dilakukan pada proyek pembangunan RSUD Sanjiwani Kabupaten Gianyar dikarenakan terjadinya perubahan desain awal pada ruang isolasi menjadi desain sesuai standarisasi COVID-19 yang menyebabkan kurangnya biaya rencana awal, sehingga perlu dilakukan penghematan biaya. Tujuan dari penelitian ini adalah untuk mengidentifikasi komponen-komponen yang berpotensi dihemat, menemukan alternatif terbaik pengganti desain awal, dan mengetahui besarnya penghematan biaya setelah dilakukan penerapan VE dengan harapan dapat memberikan penghematan yang signifikan, sehingga tercapainya biaya yang efisien dan mutu yang optimal tanpa merubah fungsi dari gedung rumah sakit.

\section{KONSEP VALUE ENGINEERING}

Value Engineering (VE) merupakan suatu pendekatan tim profesional yang dalam penerapannya berorientasi pada fungsi dan dilakukan secara sistematis dengan tujuan untuk meningkatkan nilai (value) suatu produk serta mengurangi biayanya, tetapi tetap mempertahankan persyaratan kinerja atau kualitas yang ditetapkan (SAVE, 2007). Menurut Kelly et al., (2008) menyatakan konsep utama metodologi VE terletak pada nilai dengan hubungan antara fungsi dan biaya seperti persamaan berikut:

$$
\text { Value }=\frac{\text { Fungsi }}{\text { Biaya }}
$$

Dengan mengacu pada Standard Society of American Value Engineering (SAVE, 2007), ditetapkan bahwa metodologi VE yang sistematis dan berpedoman pada rencana kerja (job plan) dibagi menjadi 3 tahap yaitu tahap sebelum studi (pre-workshop), tahap studi (workshop), dan tahap setelah studi (post-workshop). Tahap studi merupakan implementasi dari rencana kerja yang terdiri dari enam fase yaitu fase informasi, fase analisis fungsi, fase kreativitas, fase evaluasi, fase pengembangan, dan fase presentasi seperti pada Gambar 1.

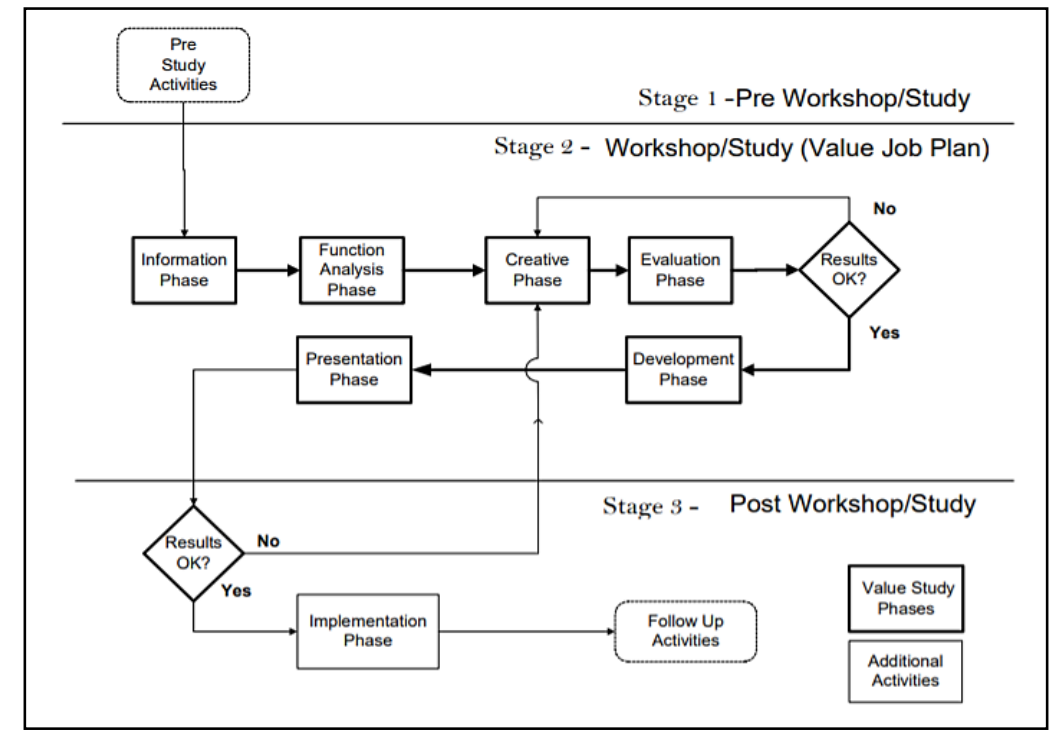

Gambar 1. Tahapan Studi Value Engineering

Sumber: SAVE (2007) 


\subsection{Diagram Pareto}

Diagram Pareto adalah sebuah diagram batang yang dipadukan dengan diagram garis untuk mengukur parameter yang ditinjau sehingga menunjukkan parameter paling dominan. Diagram batang menunjukkan nilai aktual, sedangkan diagram garis menunjukkan nilai persentase kumulatif dari setiap parameter yang ditinjau. Diagram ini membantu mengelompokkan item-item pekerjaan yang memenuhi kriteria untuk dilakukan analisis VE yaitu item - item pekerjaan dengan biaya komulatif sebesar $80 \%$ dari total biaya keseluruhan.

\subsection{Function Analysis System Technique (FAST) Diagram}

FAST diagram adalah sebuah gambar tentang fungsi subsistem dari sebuah komponen yang menunjukkan hubungan spesifik diantara semua fungsi dan memperlihatkan dengan jelas apa yang dilakukan subsistem tersebut (Kasi and Snodgrass, 1994). FAST diagram digunakan untuk menguji validitas fungsi dan memastikan bahwa semua fungsi siap untuk dianalisis dengan menyebarkan pertanyaan-pertanyaan logis seperti: bagaimana, mengapa, kapan, dan apa yang dapat menciptakan inovasi serta dapat merangsang pembentukan ide-ide kreatif.

\subsection{Analytical Hierarchy Process (AHP)}

AHP merupakan suatu model pendukung keputusan yang menguraikan masalah multi-faktor atau multikriteria yang kompleks menjadi suatu hirarki sehingga permasalahan tampak lebih terstruktur dan sistematis (Saaty, 1990). Metode AHP menggunakan konsep perbandingan berpasangan (pairwise comparison), yaitu proses membandingkan antara dua kriteria yang perlu dipertimbangkan untuk melakukan suatu pengambilan keputusan (decision making). Perbandingan dilakukan berdasarkan kebijakan pembuat keputusan dengan menilai tingkat kepentingan satu elemen terhadap elemen lainnya. Dalam menentukan nilai kepentingan relatif antar elemen digunakan skala bilangan dari 1 sampai 9 (Saaty, 2008). Untuk dapat menentukan data yang diambil konsisten maka dilakukan uji konsistensi. Dalam AHP yang diukur adalah rasio konsistensi (CR) dengan melihat indeks konsistensi (CI). Konsistensi diharapkan yang mendekati sempurna sehingga menghasilkan keputusan yang mendekati valid dengan ketentuan nilai CR $\leq 0,1$ atau 10\% (Saaty, 1994).

\section{$2.4 \quad$ Life Cycle Cost (LCC)}

LCC atau biaya siklus hidup merupakan teknik yang diteliti dan dikembangkan untuk memungkinkan evaluasi dan perbandingan biaya konstruksi, operasi, dan pemeliharaan bangunan komersial selama masa pakainya (International Consulting Lancaster House, 1984). LCC akan lebih efektif jika dilakukan pada tahap awal karena masih ada peluang untuk membuat keputusan yang tepat dan memengaruhi biaya (Kishk et al., 2003). LCC sangat penting untuk setiap proyek karena membantu dalam pengambilan keputusan untuk memilih alternatif terbaik di antara sejumlah alternatif tertentu (Al-Yafei et al., 2017). LCC dari item yang diperhitungkan selama masa investasi dengan dari seluruh biaya-biaya yang relevan dengan item tersebut berdasar pada pertimbangan Time Value of Money yang dihitung berdasarkan jumlah uang pada suatu waktu tertentu, periode waktu yang ditinjau, dan tingkat suku bunga yang dikenakan.

\section{METODE}

Penelitian ini menggunakan metode deskriptif kuantitatif yaitu metode penelitian yang menggambarkan subjek ataupun objek yang diteliti dengan menggunakan hasil analisis data berupa angka, dimana tiap tahapan merupakan bagian yang menentukan untuk melanjutkan ke tahapan berikutnya.

Penelitian diawali dengan tahap informasi berupa pengumpulan data sekunder (gambar rencana, RAB, spesifikasi teknis) yang diperoleh dari pihak pengguna maupun konsultan perencana serta beberapa penelitian yang terkait dengan topik tersebut. Selanjutnya data tersebut diolah dengan menggunakan metode pareto untuk mengidentifikasi item-item pekerjaan yang akan dilakukan analisis fungsi pada tahap berikutnya. Tahap analisis fungsi dilakukan untuk mendapatkan fungsi-fungsi dasar dari item yang dipilih dengan menggunakan metode FAST Diagram. Tahapan selanjutnya adalah tahap kreatifitas dengan melakukan brainstorming, tinjauan lapangan, dan inovasi-inovasi teknologi guna mendapatkan desain alternatif dari item-item pekerjaan yang telah diidentifikasi sebelumnya dengan mempertahankan fungsi dasar. Setelah mendapatkan beberapa alternatif desain maka dilanjutkan ke tahap evaluasi dengan menggunakan metode AHP yaitu membandingkan setiap desain alternatif yang terkumpul berdasarkan kriteria subjek pembanding untuk mendapatkan desain alternatif terbaik, sehingga alternatif yang dipilih layak digunakan. Kemudian dilanjutkan dengan tahap pengembangan yang bertujuan untuk menganalisis lebih lanjut alternatif yang dipilih dengan melakukan kombinasi terhadap setiap alternatif yang dipilih untuk mendapatkan suatu opsi alternatif yang memberikan pilihan terbaik dan dengan biaya termurah hingga menjadi usulan yang lengkap menggunakan metode Life Cycle Cost (LCC). Pada tahap akhir yaitu tahap presentasi dilakukan pelaporan hasil sampai pada tahap pengembangan dengan memaparkan keuntungan alternatif yang dipilih dan besarnya potensi penghematan setelah dilakukan analisis VE. 


\section{HASIL DAN PEMBAHASAN}

\subsection{Diagram Pareto}

Berdasarkan perangkingan item-item pekerjaan mulai dari biaya tertinggi hingga terendah, maka didapat ruang lingkup pekerjaan VE dengan biaya komulatif mencapai $82,70 \%$ yaitu pekerjaan struktur beton, pekerjaan dinding, pekerjaan lantai, dan pekerjaan kusen, pintu, jendela sesuai diagram batang berwarna biru dengan batasan garis merah pada Gambar 2.

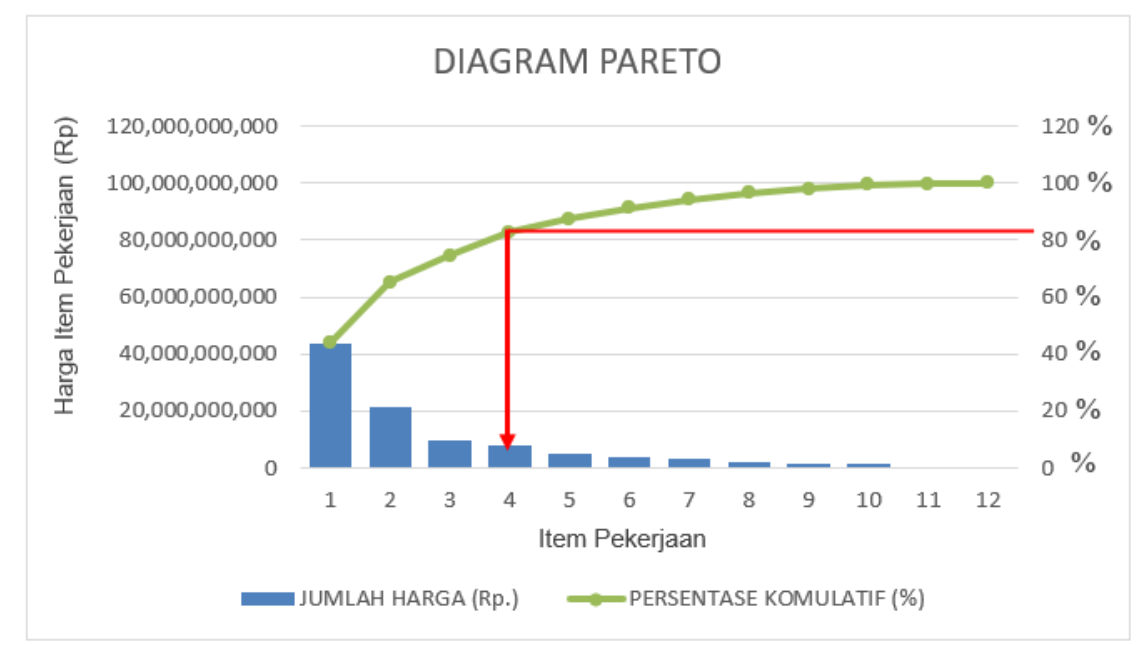

Gambar 2. Diagram Pareto Keseluruhan Item Pekerjaan

\subsection{FAST Diagram}

Pada Gambar 3 dijelaskan bahwa ruang lingkup masalah dan lintasan kritis dari kiri ke kanan berdasarkan pada fungsi dasar pekerjaan struktur beton yaitu sebagai struktur utama bangunan. Terdapat fungsi sekunder yang terhubung dalam lintasan kritis berturut-turut yaitu pemilihan metode pelaksanaan (fungsi terkait kemudahan pemasangan), dan kontrol terhadap waste material.

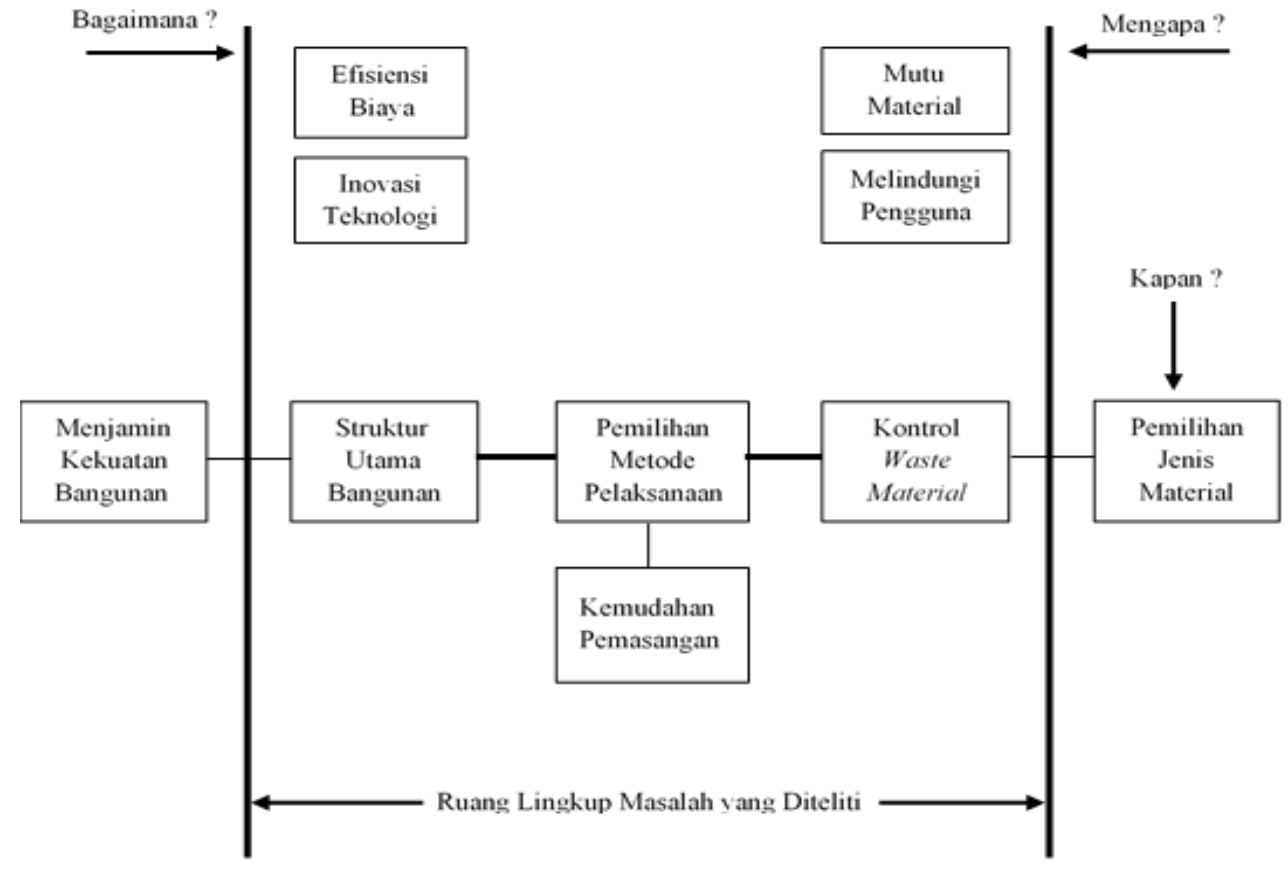

Gambar 3. FAST Diagram Pekerjaan Struktur Beton

Pada pekerjaan dinding juga didapat fungsi dasar yaitu sebagai pembatas ruangan atau membagi ruangan, pada pekerjaan lantai didapat fungsi dasar yaitu sebagai penutup dasar sehingga menjamin kenyamanan pengguna, serta pada pekerjaan kusen, pintu, jendela didapat fungsi dasar yaitu untuk menyediakan kontrol terhadap akses keluar masuk orang, cahaya, maupun udara dalam ruangan. 


\subsection{Desain Alternatif}

Berdasarkan hasil brainstorming, tinjauan lapangan, dan inovasi-inovasi teknologi diperoleh 2 alternatif desain pada pekerjaan struktur beton yaitu balok precast dengan pelat metal deck dan balok precast dengan pelat precast sebagai pengganti balok dan pelat konvensional. Pada pekerjaan dinding diperoleh 2 alternatif desain yaitu dinding batako dan dinding panel beton sebagai pengganti dinding bata ringan. Pada pekerjaan lantai diperoleh 2 alternatif desain yaitu lantai keramik dan lantai vinyl sebagai pengganti lantai granite tile. Pada pekerjaan kusen, pintu, jendela diperoleh 2 alternatif desain yaitu kusen dan daun pintu aluminium, kusen dan daun pintu UPVC sebagai pengganti kusen aluminium dan daun pintu plywood lapis HPL.

\subsection{Analytical Hierarchy Process (AHP)}

Setelah mendapatkan beberapa desain alternatif, maka dilanjutkan dengan mengevaluasi masing-masing desain alternatif tersebut berdasarkan kriteria subjek pembanding menggunakan metode AHP.

Pada pekerjaan struktur beton balok dan pelat ditampilkan pohon hierarki seperti pada Gambar 4.

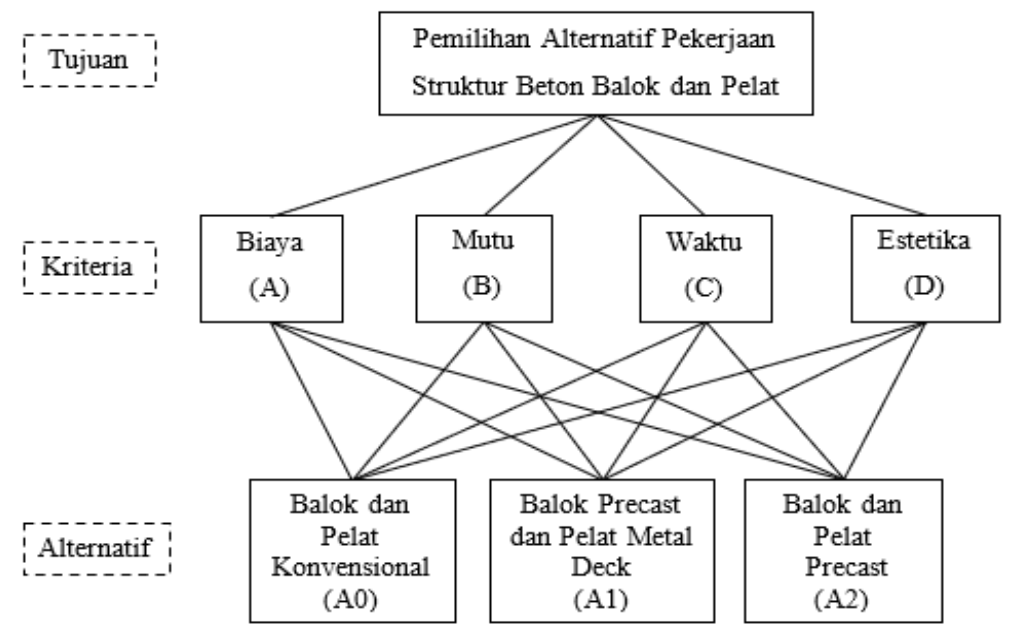

Gambar 4. Pohon Hirarki Pekerjaan Struktur Beton Balok dan Pelat

Setelah penyusunan hierarki selesai, maka dilanjutkan dengan melakukan perbandingan antara elemenelemen dengan memperhatikan pengaruh elemen lain pada level di atasnya. Matriks perbandingan berpasangan kriteria untuk pekerjaan struktur beton balok dan pelat yang dapat dilihat pada Tabel 1.

Tabel 1. Matriks Perbandingan Kriteria pada Pekerjaan Struktur Beton Balok dan Pelat

\begin{tabular}{ccccc}
\hline \multirow{2}{*}{ Kriteria } & Biaya & Mutu & Waktu & Estetika \\
\cline { 2 - 5 } & $\mathbf{A}$ & $\mathbf{B}$ & $\mathbf{C}$ & $\mathbf{D}$ \\
\hline $\mathbf{A}$ & 1,00 & 0,39 & 3,00 & 5,00 \\
B & 2,57 & 1,00 & 2,00 & 5,33 \\
$\mathbf{C}$ & 0,33 & 0,50 & 1,00 & 3,67 \\
D & 0,20 & 0,19 & 0,27 & 1,00 \\
\hline Jumlah & $\mathbf{4 , 1 0}$ & $\mathbf{2 , 0 8}$ & $\mathbf{6 , 2 7}$ & $\mathbf{1 5 , 0 0}$ \\
\hline
\end{tabular}

Matriks perbandingan berpasangan dinormalisasi untuk mencari nilai vektor eigen dan menjumlahkan nilai-nilai dari setiap baris, lalu membaginya dengan jumlah elemen untuk mendapatkan rata-rata (bobot prioritas) yang dapat dilihat pada Tabel 2.

Tabel 2. Nilai Vektor Eigen pada Pekerjaan Struktur Beton Balok dan Pelat

\begin{tabular}{|c|c|c|c|c|c|c|}
\hline \multirow{2}{*}{ Kriteria } & \multicolumn{4}{|c|}{ Nilai Vektor Eigen } & \multirow{2}{*}{ Jumlah } & \multirow{2}{*}{$\begin{array}{c}\text { Bobot } \\
\text { Prioritas }\end{array}$} \\
\hline & $\mathbf{A}$ & B & $\mathbf{C}$ & D & & \\
\hline $\mathbf{A}$ & 0,244 & 0,187 & 0,478 & 0,333 & 1,243 & 0,311 \\
\hline B & 0,626 & 0,482 & 0,319 & 0,356 & 1,782 & 0,446 \\
\hline $\mathbf{C}$ & 0,081 & 0,241 & 0,159 & 0,244 & 0,726 & 0,181 \\
\hline D & 0,049 & 0,090 & 0,043 & 0,067 & 0,249 & 0,062 \\
\hline \multicolumn{6}{|c|}{ Total } & 1,000 \\
\hline
\end{tabular}


Kemudian memeriksa konsistensi hierarkhi, konsistensi diharapkan yang mendekati sempurna agar menghasilkan keputusan yang mendekati valid dengan ketentuan nilai $\mathrm{CR} \leq 0,1$ atau $10 \%$.

a. Perkalian matriks perbandingan dengan bobot prioritas

$\left|\begin{array}{llll}1,00 & 0,39 & 3,00 & 5,00 \\ 2,57 & 1,00 & 2,00 & 5,33 \\ 0,33 & 0,50 & 1,00 & 3,67 \\ 0,20 & 0,19 & 0,27 & 1,00\end{array}\right| \times\left|\begin{array}{c}0,311 \\ 0,446 \\ 0,181 \\ 0,062\end{array}\right|=\left|\begin{array}{c}1,340 \\ 1,940 \\ 0,736 \\ 0,257\end{array}\right|$

b. Menguji Consistency Index (CI)

$$
\lambda \operatorname{Max}=\frac{\left(\frac{1,340}{0,311}\right)+\left(\frac{1,940}{0,446}\right)+\left(\frac{0,736}{0,181}\right)+\left(\frac{0,257}{0,062}\right)}{4}=4,214
$$

Maka didapat:

$$
\mathrm{CI}=\frac{\lambda \mathrm{Max}-\mathrm{n}}{\mathrm{n}-1}=\frac{4,214-4}{4-1}=0,071
$$

c. Menguji Consisteny Ratio (CR)

$$
\mathrm{CR}=\frac{\mathrm{CI}}{R I}=\frac{0,071}{0,9}=0,079 \leq 0,1 \ldots \ldots \text { oK (memenuhi syarat) }
$$

Sintesa pembobotan kriteria untuk pekerjaan struktur beton balok dan pelat dilakukan dengan mengkuadratkan matriks perbandingan berpasangan, kemudian nilai-nilai dari setiap baris dijumlahkan dan

\begin{tabular}{|c|c|c|c|c|c|c|c|}
\hline \multirow{2}{*}{ Kriteria } & Biaya & Mutu & Waktu & Estetika & \multirow{2}{*}{ Jumlah } & \multirow{2}{*}{ Bobot } & \multirow{2}{*}{ Rangking } \\
\hline & $\mathbf{A}$ & B & C & D & & & \\
\hline $\mathbf{A}$ & 4,00 & 3,22 & 8,14 & 23,07 & 38,43 & 0,319 & 2 \\
\hline B & 6,88 & 4,00 & 13,17 & 30,86 & 54,90 & 0,455 & 1 \\
\hline C & 2,69 & 1,82 & 4,00 & 11,67 & 20,17 & 0,167 & 3 \\
\hline D & 0,97 & 0,59 & 1,52 & 4,00 & 7,08 & 0,059 & 4 \\
\hline \multicolumn{5}{|c|}{ TOTAL } & 120,59 & 1,000 & \\
\hline
\end{tabular}
dihitung rata-ratanya sehingga didapat bobot dari setiap kriteria seperti pada Tabel 3.

Tabel 3. Sintesa Pembobotan Kriteria Pekerjaan Struktur Beton Balok dan Pelat

Setelah matriks level dua selesai dibuat sampai pada perhitungan bobot prioritasnya dilanjutkan pada perbandingan antar elemen pada level tiga dengan pertimbangan level dua. Berdasarkan hasil brainstorming dengan para ahli di bidang konstruksi maka didapat jumlah penilaian alternatif berdasarkan kriteria pembanding

\begin{tabular}{|c|c|c|c|c|c|c|c|c|}
\hline \multirow{3}{*}{ No } & \multirow{3}{*}{ Alternatif } & \multirow{3}{*}{ Kode } & \multicolumn{4}{|c|}{ Bobot Kriteria } & \multirow{3}{*}{$\begin{array}{l}\text { Total } \\
\text { Skor }\end{array}$} & \multirow{3}{*}{ Rangking } \\
\hline & & & $\mathbf{A}$ & B & $\mathbf{C}$ & D & & \\
\hline & & & 0,319 & 0,455 & 0,167 & 0,059 & & \\
\hline 1 & Balok dan Pelat Konvensional & A0 & 2 & 3 & 1 & 2 & 2,288 & 3 \\
\hline 2 & Balok Precast dan Pelat Metal Deck & A1 & 3 & 3 & 2 & 2,333 & 2,794 & 1 \\
\hline 3 & Balok dan Pelat Precast & A2 & 1 & 3 & 3 & 2,333 & 2,323 & 2 \\
\hline
\end{tabular}
yang dapat dilihat pada Tabel 4.

Tabel 4. Hasil AHP Untuk Pekerjaan Struktur Beton Balok dan Pelat

Pada Tabel 4 didapat kesimpulan bahwa alternatif 1 yaitu balok precast dan pelat metal deck adalah pilihan alternatif terbaik karena memiliki bobot dengan nilai tertinggi yaitu sebesar 2,794. Sedangkan desain awal yaitu balok dan pelat konvensional memiliki bobot sebesar 2,288 dimana desain awal memiliki kekurangan dari kriteria biaya, waktu, dan estetika. Jadi pemilihan alternatif 1 layak untuk digunakan. 
Pada pekerjaan dinding juga digunakan metode AHP diperoleh hasil bahwa rencana awal yaitu dinding bata ringan adalah pilihan terbaik karena memiliki bobot dengan nilai tertinggi yaitu sebesar 2,466 diikuti alternatif 2 dan alternatif 1 yang memiliki bobot masing-masing sebesar 2,342 dan 1,866. Jadi pemilihan rencana awal (dinding bata ringan) layak untuk digunakan seperti yang ditampilkan pada Tabel 5.

Tabel 5. Hasil AHP Untuk Pekerjaan Dinding

\begin{tabular}{|c|c|c|c|c|c|c|c|c|}
\hline \multirow{3}{*}{ No } & \multirow{3}{*}{ Alternatif } & \multirow{3}{*}{ Kode } & \multicolumn{4}{|c|}{ Bobot Kriteria } & \multirow{3}{*}{$\begin{array}{l}\text { Total } \\
\text { Skor }\end{array}$} & \multirow{3}{*}{ Rangking } \\
\hline & & & $\mathbf{A}$ & $\mathbf{B}$ & $\mathbf{C}$ & $\mathbf{D}$ & & \\
\hline & & & 0,251 & 0,387 & 0,283 & 0,079 & & \\
\hline 1 & Dinding Bata Ringan & A0 & 2 & 3 & 2 & 3 & 2,466 & 1 \\
\hline 2 & Dinding Batako & A1 & 3 & 1,667 & 1 & 2,333 & 1,866 & 3 \\
\hline 3 & Dinding Panel Beton & $\mathrm{A} 2$ & 1 & 2,667 & 3 & 2,667 & 2,342 & 2 \\
\hline
\end{tabular}

Pada pekerjaan lantai dengan menggunakan metode AHP diperoleh hasil bahwa alternatif 1 yaitu lantai keramik adalah pilihan alternatif terbaik karena memiliki bobot dengan nilai tertinggi yaitu sebesar 2,369. Sedangkan desain awal yaitu lantai granite tile memiliki bobot sebesar 2,360 dimana desain awal memiliki kekurangan dari kriteria biaya dan waktu. Jadi pemilihan alternatif 1 layak untuk digunakan seperti pada Tabel 6.

Tabel 6. Hasil AHP Untuk Pekerjaan Lantai

\begin{tabular}{ccccccccc}
\hline & & & \multicolumn{9}{c}{ Bobot Kriteria } & & \\
\cline { 4 - 6 } No & \multirow{2}{*}{ Alternatif } & Kode & $\mathbf{A}$ & $\mathbf{B}$ & $\mathbf{C}$ & $\mathbf{D}$ & $\begin{array}{c}\text { Total } \\
\text { Skor }\end{array}$ & Rangking \\
\cline { 4 - 7 } & & 0,405 & 0,135 & 0,082 & 0,378 & & \\
\hline 1 & Lantai Granite Tile & $\mathrm{A} 0$ & 2 & 3 & 1,667 & 2,667 & 2,360 & 2 \\
2 & Lantai Keramik & $\mathrm{A} 1$ & 3 & 2,667 & 2 & 1,667 & 2,369 & 1 \\
3 & Lantai Vinyl & $\mathrm{A} 2$ & 1 & 3 & 3 & 2,667 & 2,064 & 3 \\
\hline
\end{tabular}

Pada pekerjaan kusen, pintu, jendela dengan menggunakan metode AHP diperoleh hasil bahwa alternatif 1 yaitu kusen dan daun pintu aluminium adalah pilihan alternatif terbaik karena memiliki bobot dengan nilai tertinggi yaitu sebesar 2,494. Sedangkan desain awal yaitu kusen aluminium dan daun pintu HPL memiliki bobot 2,384 yang memiliki kekurangan dari kriteria mutu dan waktu. Jadi pemilihan alternatif 1 layak untuk digunakan seperti yang ditampilkan pada Tabel 7.

Tabel 7. Hasil AHP Untuk Pekerjaan Kusen, Pintu, dan Jendela

\begin{tabular}{|c|c|c|c|c|c|c|c|c|}
\hline \multirow{3}{*}{ No } & \multirow{3}{*}{ Alternatif } & \multirow{3}{*}{ Kode } & \multicolumn{4}{|c|}{ Bobot Kriteria } & \multirow{3}{*}{$\begin{array}{l}\text { Total } \\
\text { Skor }\end{array}$} & \multirow{3}{*}{ Rangking } \\
\hline & & & $\mathbf{A}$ & B & $\mathbf{C}$ & D & & \\
\hline & & & 0,217 & 0,367 & 0,249 & 0,167 & & \\
\hline 1 & $\begin{array}{l}\text { Kusen Aluminium dan } \\
\text { Daun Pintu HPL }\end{array}$ & A0 & 3 & 2 & 2 & 3 & 2,384 & 2 \\
\hline 2 & $\begin{array}{l}\text { Kusen dan Daun Pintu } \\
\text { Aluminium }\end{array}$ & A1 & 2 & 2,667 & 3 & 2 & 2,494 & 1 \\
\hline 3 & $\begin{array}{l}\text { Kusen dan Daun Pintu } \\
\text { UPVC }\end{array}$ & $\mathrm{A} 2$ & 1 & 3 & 3 & 1,333 & 2,287 & 3 \\
\hline
\end{tabular}

\subsection{Life Cycle Cost (LCC)}

LCC memperhitungkan biaya perawatan berkala yang dilakukan setiap 5 tahun sekali selama masa guna bangunan (40 tahun) dengan asumsi kerusakan bervariasi terhadap jenis item pekerjaan yang ditinjau dan memperhitungkan nilai inflasi sebesar 4,58\% dengan asumsi bunga $12 \%$. Hasil perhitungan LCC pada pekerjaan dinding diperoleh biaya yang paling efisien adalah alternatif dinding batako yaitu sebesar Rp8.931.326.085, menghasilkan penghematan sebesar Rp1.736.491.510,35 atau 16,28\% dibandingkan desain awal. Pada pekerjaan lantai diperoleh biaya yang paling efisien adalah alternatif lantai keramik yaitu sebesar Rp4.247.420.723 dengan penghematan sebesar Rp833.444.439,01 atau 16,40\% dibanding desain awal. Pada pekerjaan kusen, pintu, jendela diperoleh biaya paling efisien adalah alternatif kusen dan daun pintu aluminium yaitu sebesar Rp2.547.550.727, menghasilkan penghematan sebesar Rp117.598.489,53 atau 4,41\% dibandingkan desain awal. 
Berdasarkan hasil dan pembahasan yang telah dilakukan, maka diperoleh simpulan sebagai berikut:

1. Dari hasil analisa pareto item pekerjaan yang dapat dilakukan VE adalah pekerjaan struktur beton, pekerjaan pasangan dinding, pekerjaan penutup lantai, dan pekerjaan kusen, pintu, jendela.

2. Alternatif terbaik untuk masing-masing item pekerjaan tersebut yaitu:

a. Pekerjaan Struktur Beton

Pada pekerjaan struktur beton didapat alternatif pengganti balok dan pelat konvensional menjadi balok precast dan pelat metal deck karena dapat mengurangi waste material hingga 92,10\% dan mampu menghasilkan penghematan sebesar Rp1.046.477.531,18 atau 4,47\%.

b. Pekerjaan Pasangan Dinding

Pada pekerjaan dinding digunakan alternatif pasangan dinding bata ringan sesuai rencana awal karena dinding bata ringan memiliki massa yang ringan dan tidak membebani struktur yang signifikan. Bata ringan juga lebih tahan terhadap panas dan peredam suara yang baik, sehingga cocok digunakan pada rumah sakit.

c. Pekerjaan Penutup Lantai

Pada pekerjaan lantai digunakan alternatif lantai keramik sebagai pengganti lantai granite tile karena biayanya lebih murah. Disamping itu juga lantai keramik dipasang pada area yang tidak memerlukan sterilisasi tinggi, sehingga pemilihan keramik layak digunakan. Penggunaaan lantai keramik mampu menghasilkan penghematan sebesar Rp1.058.532.387,51 atau 34,64\%.

d. Pekerjaan Kusen, Pintu, dan Jendela

Pada pekerjaan kusen, pintu, dan jendela digunakan alternatif daun pintu aluminium sebagai pengganti daun pintu plywood lapis HPL karena aluminium tahan terhadap korosi, rayap, dan tidak mudah memuai maupun susut. Total harga awal pintu aluminium lebih mahal sebesar Rp61.974.755,29 atau 3,87\%, namun setelah dilakukan perhitungan LCC (memperhitungkan biaya perawatan) didapat penghematan sebesar Rp117.598.489,53 atau 4,41\%.

3. Berdasarkan hasil pemilihan alternatif terbaik setelah dilakukan VE, diperoleh penghematan biaya sebesar Rp2.043.035.163,40 atau 1,50\%.

\section{DAFTAR PUSTAKA}

Al-Yafei, E., Ogunlana, S., Oyegoke, A. 2017. Application of Value Engineering and Life Cycle Costing Techniques for Offshore Topside Facility Projects: Towards Sustainability. Society of Petroleum Engineers - SPE Kuwait Oil and Gas Show and Conference 2017, (January).

Bari, N.A.A., Yusuff, R., Ismail, N., Jaapar, A., Ahmad, R. 2012. Factors Influencing the Construction Cost of Industrialised Building System (IBS) Projects. Procedia - Social and Behavioral Sciences, 35(December 2011): 689-696.

Dell'Isola, A.J. 1982. Value Engineering in The Construction Industry. Van Nostrand Reinhold.

Diputera, I.G.A., Putera, I.G.A.A., Dharmayanti, G.A.P.C. 2018. Penerapan Value Engineering (Ve) Pada Proyek Pembangunan Taman Sari Apartement. Jurnal Spektran, 6(2): 210-216.

International Consulting Lancaster House. 1984. Life Cycle Costing, Value Engineering \& Value Management Studies.

Jaya, N.M., Yana, A.A.G.A., Triswandana, I.W.G.E. 2019. Penerapan Rekayasa Nilai Pada Proyek Pembangunan Gedung Sekolah (Studi Kasus Pembangunan Gedung Sekolah Sanur Independent School). Jurnal Spektran, 7(1): 244-253.

Kasi, M., Snodgrass, T.J. 1994. An Introduction to value analysis and value engineering for Architects, Engineers, and Builders, Civil and Environmental Engineering C240-A362.

Kelly, J., Male, S., Graham, D. 2008. Value Management of Construction Projects. In Value Management of Construction Projects.

Kishk, M., Alhajj, A., Pollock, R., Aouad, G., Bakis, N., \& Sun, M. 2003. Whole Life Cycle Costing in Construction. A State of The Art Review, 4, no 18: 1-39.

Klinger, M., Susong, M., Trial, A.B.A.T., Section, I.P. 2006. The Construction Project: Phases, People, Terms, Paperwork, Processes. ABA Tort Trial \& Insurance Practice.

Saaty, T.L. 1990. How to Make a Decision: The Analytic Hierarchy Process. European Journal of Operational Research, .

Saaty, T.L. 1994. How To Make a Decision : The Analytic Hierarcy Process. Interfaces, 24(6): $19-43$.

Saaty, T.L. 2008. Decision Making with The Analytic Hierarchy Process. Int. J. Services Sciences, Vol. 1, No. 1, 1: 83-98.

SAVE. 2007. Value Standard and the Body of Knowledge. In SAVE International Value Standard.

Serrador, P. 2012. The Importance of the Planning Phase to Project Success. Paper Presented at PMI Global Congress, . 